\title{
An atypical case of proventricular dilatation in a Red-and-green Macaw (Ara chloropterus)
}

\author{
Een atypisch geval van kliermaagdilatatie bij een Groenvleugelara \\ (Ara chloropterus)
}

${ }^{1}$ T. Hellebuyck, ${ }^{1}$ L. Geerinckx, ${ }^{1} \mathrm{~J}$. Simard, ${ }^{1} \mathrm{M}$. Verlinden, ${ }^{2}$ A. Van Caelenberg

${ }^{1}$ Department of Pathology, Bacteriology and Avian Diseases,

${ }^{2}$ Department of Medical Imaging of Domestic Animals,

Faculty of Veterinary Medicine, Ghent University, Salisburylaan 133, B-9820 Merelbeke, Belgium

Tom.Hellebuyck@UGent.be

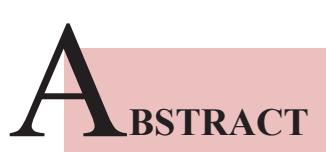

A Red-and-green Macaw (Ara chloropterus) was presented with regurgitation and passage of undigested seeds in the feces. Radiographic examination revealed dilatation of the proventriculus. Contrast radiography was performed and revealed that the proventricular dilatation and associated clinical signs resulted from circumferential thickening of the proventricular wall leading to severe narrowing of the lumen of the proventriculus. Testing for parrot bornavirus $(\mathrm{PaBV})$ was negative. After the initiation of antimicrobial treatment because of suspected bacterial overgrowth, all clinical signs resolved two weeks after the start of the treatment, and radiographs taken four months after initial presentation revealed a normal appearance and size of the proventriculus. In the present case, bacterial proventriculitis associated with hyperplasia of the proventricular wall was put forward as a final but presumptive diagnosis highlighting the need to differentiate bacterial proventriculitis from other causes of proventricular dilatation in macaws.

\section{SAMENVATTING}

Een Groenvleugelara (Ara chloropterus) werd aangeboden omwille van regurgitatie en de aanwezigheid van onverteerde zaden in de mest. Kliermaagdilatatie werd radiografisch vastgesteld. Contrastradiografie werd uitgevoerd en toonde aan dat de dilatatie van de kliermaag en de geassocieerde klinische symptomen het resultaat waren van een circulaire verdikking van de kliermaagwand met een ernstige vernauwing van het lumen van de kliermaag tot gevolg. Testen voor parrot bornavirus (PaBV) waren negatief. Twee weken na het opstarten van een antimicrobiële behandeling omwille van vermoedelijke bacteriële overgroei, verdwenen alle klinische symptomen. Een normaal uitzicht en een fysiologische afmeting van de kliermaag werden vastgesteld op basis van radiografieën die vier maanden na de initiële presentatie genomen werden. Bacteriële proventriculitis geassocieerd met hyperplasie van de kliermaagwand werd vooropgesteld als definitieve maar vermoedelijke diagnose. In deze casuïstiek wordt het belang benadrukt om bacteriële proventriculitis te differentiëren van andere oorzaken van kliermaagdilatatie bij ara's.

\section{HISTORY}

A four-year-old, male Red-and-green Macaw (Ara chloropterus) with a body weight of $1.165 \mathrm{~kg}$ was presented with inappetence, weight loss, regurgitation and the presence of undigested seeds in the feces. The macaw was fed Harrison's high potency coarse pel- lets (Harrison's Bird Foods, Tennessee, USA) combined with a commercial seed mixture for parrots and fruit and vegetables on a daily basis. The parrot was housed individually and was left outside of the cage with access to a playpen during the largest part of the day. One month prior to initial presentation, the macaw started to show a decreased appetite, occasional 
regurgitation and the passage of undigested seeds in the feces. Polymerase chain reaction (PCR) testing for psittacine beak and feather disease, parrot bornavirus (PaBV), polyomavirus and Chlamydia psittaci infection was negative and $\mathrm{PaBV}$ serum antibodies could not be detected through ELISA testing. The macaw was administered doxycycline (Vibramycine, $40 \mathrm{mg} /$ $\mathrm{kg}$, intramuscularly, once), meloxicam (Metacam, 0.2 $\mathrm{mg} / \mathrm{kg}$, per orally, SID, one week) and nystatin (Nilstat, $100000 \mathrm{UI} /$ liter drinking water, one week). As no effect was seen of the installed treatment and as the frequency of regurgitation increased progressively, the macaw was referred to a veterinary teaching hospital two months after the clinical signs had initially been noted. During clinical examination, the macaw displayed alert and active behavior, had a body weight of $1.020 \mathrm{~kg}$ and a moderate feeding condition but showed no other clinical abnormalities. Radiographic examination revealed pronounced dilatation and increased opacity of the proventriculus. The ratio between the height of the proventriculus and the height of the sternum was 0.8 , exceeding the physiological reference ratio of 0.52 as suggested by Dennison et al. (2008) and Geerinckx et al. (2019). In addition to moderately distended and gas-filled intestinal loops, mild hepatomegaly and splenomegaly were observed. Blood was collected from the jugular vein for a serum biochemistry profile and hematologic evaluation at the time of physical examination. Abnormal findings were limited to moderate leukocytosis with heterophilia and mild hypoglycemia (Samour, 2016). PCR and serology for PaBV were repeated but yielded negative results, and plasma concentrations for zinc and lead were within physiological reference intervals (Lightfoot and Yeager, 2008).

Contrast radiography was performed to allow a better assessment of the proventriculus as well as the gastro-intestinal transit time using iopromide (Ultravist, $350 \mathrm{mg} / \mathrm{ml}$, Berlex, Germany), a iodinated contrast agent. The contrast medium was given through gavage of the crop at a dose of $2.5 \mathrm{ml} / \mathrm{kg}$ body weight. Radiographs were made at the moment of adminis-

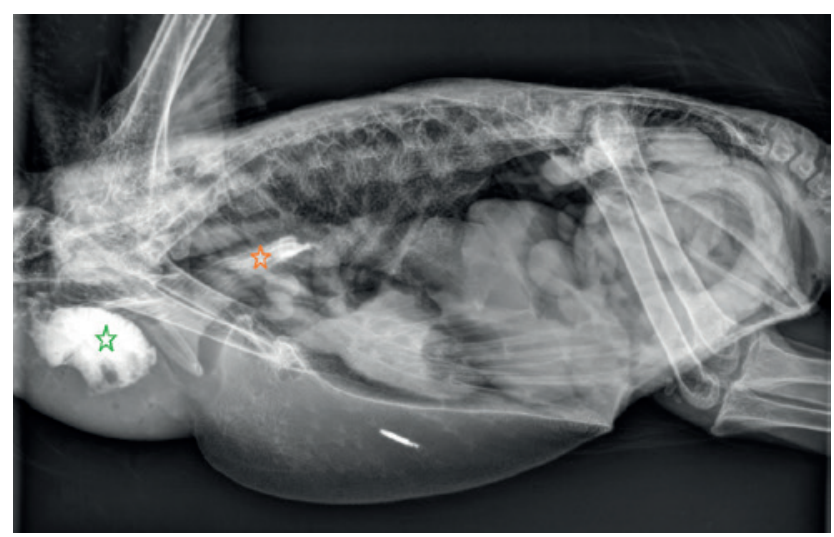

Figure 1. Lateral post-contrast radiograph T0: contrast medium is present within the crop (green asterix) and partially within the esophagus (orange asterix). tering the contrast medium (T0) and one (T1'), three (T3') and five (T5') minutes after administration. The first radiograph (T0) confirmed the presence of the radio-opaque contrast fluid in the crop (Figure 1). At T1', T3' and T5' filling of the passage of the contrast fluid from the crop to the proventriculus and filling of the proventriculus and the ventriculus were observed, respectively (Figure 2). Luminal filling and delineation of the esophagus, crop and ventriculus as well as the transit time were considered normal (VinkNooteboom, 2003; Kubiak and Forbes, 2012). However, prominent stenosis of the proventricular lumen with a residual diameter of approximately $2 \mathrm{~mm}$, and marked, circumferential thickening of the proventricular wall were noticed.

Further testing for conditions that have been associated with proventricular dilatation resulting from hyperplasia of the proventricular wall in psittacines was performed, including PCR for psittacid herpesvirus-1 (PsHV-1), PCR for Cryptosporidium spp., and repeated evaluation of fecal smears for the presence of megabacteria yielded negative results. In addition, a five-days-pooled fecal sample was collected for $\mathrm{Sal}$ monella isolation and parasitological examination. No Salmonella species could be detected on brilliant green agar (BGA; Oxoid Ltd., Hampshire, United Kingdom), even after enrichment in tetrathionate broth. No endoparasites could be detected following flotation of the feces sample in a saturated salt solution.

In order to examine other causes of PDD in the macaw, such as neoplasia, mycobacteriosis and gastric mycosis (e.g. zygomycosis), the collection of gastric biopsies for histological examination and microbiological and molecular testing was advised but declined by the owner.

Although considered as a secondary finding at that time, bacterial overgrowth was suspected based on the presence of an abundant and heterogeneous population of coccoid as well as rod shaped bacteria in hemacolor stained fecal smears; antimicrobial treatment with enrofloxacin (Baytril 10\%, Bayer SA-NV,

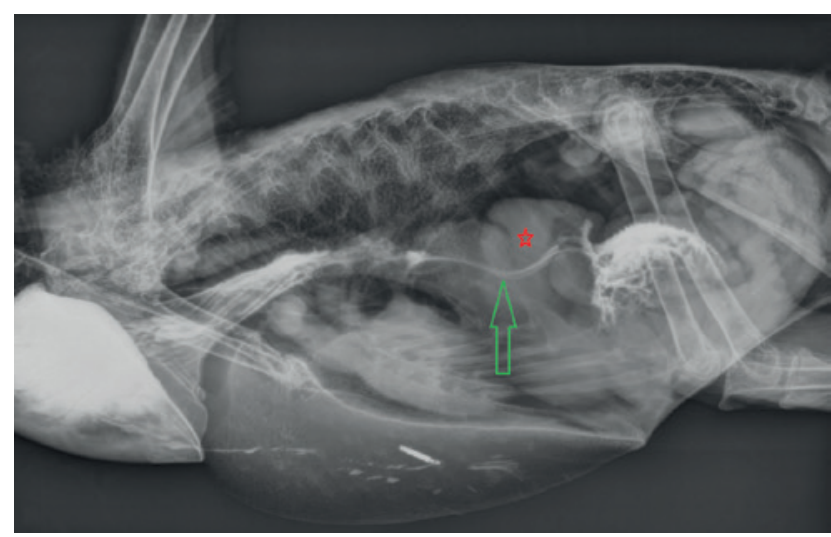

Figure 2. Lateral post-contrast radiograph T3: a small volume of contrast medium can be seen within the lumen of the proventriculus (green arrow). A thickened wall is visible (red asterix). 
Belgium, $10 \mathrm{mg} / \mathrm{kg}$, per orally, BID) was started for two weeks. At the end of this treatment, the macaw displayed a normal behavior and appetite, and regurgitation as well as the passage of undigested seeds in the feces had completely resolved. Four months after initial presentation, radiographical examination was repeated and revealed a normal appearance and size of the proventriculus (Figure 3). During a two-year follow-up period, the macaw did not show recurrence of the clinical signs. In the present case, bacterial proventriculitis associated with hyperplasia of the proventricular wall was put forward as a final but presumptive diagnosis.

\section{DISCUSSION}

In the present case, PDD is described in a Redand-green Macaw caused by hyperplasia of the proventricular wall with stenosis of the proventricular lumen resulting in clinical signs related to impaired proventricular function and passage of ingesta through the proventriculus. Based on the clinical history and findings, primary or facultative bacterial proventriculitis was considered to be the etiology of the observed gastric disorder in the macaw.

The proventriculus is the first of two stomach compartments that is found in most bird species (Langlois, 2003; Boutette and Taylor, 2004). Diseases associated with proventricular dilatation are commonly recognized in psittacines and can be associated with various infectious and non-infectious diseases (Langlois, 2003). Antemortem examination of the proventriculus however, is challenging due to its location in the cranial coelomic cavity and is mostly limited to medical imaging, mainly radiography, computed tomography and endoscopic examination (Geerinckx et al., 2019). Radiography can be used to assess size, location, contour and content of the proventriculus (Geerinckx et al., 2019). In addition, the use of contrast fluid can provide information about the gastrointestinal transit time as well as the delineation of the proventricular mucosal surface and lumen (Vink-Nooteboom, 2003; Garcia Martinez, 2007). Studies on the gastrointestinal transit time using barium contrast showed highly comparable results in healthy African grey parrots (Psittacus erithacus erithacus) and blue-fronted Amazons (Amazona aestiva) (Vink-Nooteboom, 2003; Kubiak and Forbes, 2012). Immediately following oral gavage, barium contrast is found in the crop and proventriculus. The proventriculus shows a maximal luminal filling with contrast medium of $30 \%$. After on average thirty minutes, barium contrast medium reaches the ventriculus and intestinal filling is observed after on average fifteen and ninety minutes. Intraspecies variation of the gastrointestinal transit time in birds can be related to several factors, such as age, health status, stress, diet, anesthesia and the effect of medication (Pelelo and Denson, 1993). Fluoroscopy

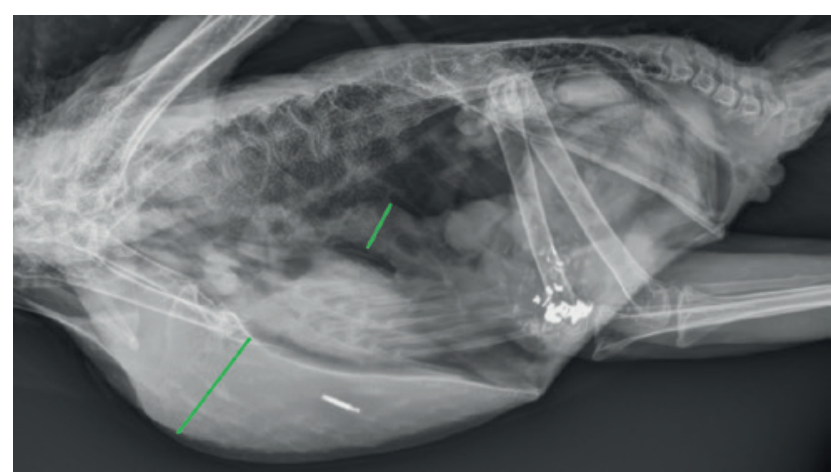

Figure 3. Lateral radiograph taken four months after initial presentation revealing a normalized ratio between the height of the proventriculus and the height of the sternum.

has some advantages compared to contrast radiography, such as a superior assessment of the gastrointestinal peristaltic movements (Ritchie et al., 2004). In the present case, contrast radiology was performed with iopromide and revealed circumferential thickening of the proventricular wall with severe stenosis of the proventricular lumen and rapid passage of the contrast medium from the crop to the ventriculus despite the pronounced stenosis of the proventricular lumen. In retrospect, the lower viscosity of iopromide in comparison to barium sulfate might explain the lastmentioned finding and did not allow adequate assessment of at least the proventricular transit time in the present case.

The radiographical abnormalities of the proventriculus in the macaw did not comply with the thin wall of the proventriculus and often dilated and gasfilled proventricular lumen that is classically seen in PaBV-associated PDD cases (Pelelo and Denson, 1993). Megabacteriosis is rarely seen in macaws, and associated abnormalities following the use of contrast-enhanced radiology are mostly limited to a narrowing between the proventriculus and the ventriculus (Werther et al., 2000; Antinoff et al., 2004). Proventricular dilatation associated with diffuse or multifocal proventricular mucosal hypertrophia and hyperplasia has been documented in psittacines and other avian species with Cryptosporidium (especially C. galli) or Spiruroidae (especially Spiroptera incerta) infection, papillomatosis and mycotic infection (e.g. zygomycosis). In those cases however, stenosis of the lumen is generally less pronounced and the mucosal proliferation often causes highly irregular delineation (Ravich et al., 2014; Terio et al., 2018). Proventricular neoplasia, such as adenoma, adenocarcinoma and carcinoma, is a relatively rare disorder in psittacines, but shows highly similar radiographical findings following the use of contrast fluid as observed in the present case (Langlois, 2003; Boutette and Taylor, 2004).

Although various primary or opportunistic infectious diseases, including PaBV infection, Macrorhabdus ornithogaster (megabacteriosis), candidiasis, sal- 
monellosis, parasitosis (e.g. Cryptosporidium spp. and Spiruroidae infection) and PsHV-1 (papillomatosis) were considered highly unlikely based on the performed tests in the present case, false negative test results should always be taken into account. This may be attributed to for instance intermittent excretion of the agent involved. Nevertheless, neoplasia, mycobacteriosis and gastric mycosis (zygomycosis) were eventually considered as the most likely cause of the gastric disorder in the present case. Although considered as the most decisive method to diagnose the these conditions, the collection of biopsies of the proventriculus is deemed to be technically challenging and highly invasive when performed by coeliotomy and gastrotomy. A more rapid and exact diagnosis might have been accomplished in a minimally invasive way by performing gastroscopy via the oral approach, allowing the inspection of the proventricular lumen and mucosal surface and the collection of biopsies for histopathological, microbiological and molecular examination (Sladakovic et al., 2017).

Based on the complete resolution of the clinical signs and radiographical signs of proventricular dilatation following antimicrobial treatment, bacterial proventriculitis was put forward as a presumptive diagnosis in the present case. Unfortunately, a causative agent could not be identified.

\section{CONCLUSION}

In conclusion, in the present case, the importance of a multidirectional approach in order to diagnose and differentiate bacterial proventriculitis from other causes of proventricular dilatation in macaws is highlighted. The use of contrast radiography may direct the initial diagnostic approach and facilitates the selection of appropriate additional diagnostic methods. A definitive diagnosis of proventricular dilatation associated with bacterial proventriculitis is challenging and should ideally rely on a combination of medical imaging and the collection of gastric biopsies for histological examination as well as for microbiological and molecular testing.

\section{REFERENCES}

Antinoff N., Filippich L.J., Speer B., Phalen D.N., Powers L.V. (2004). Diagnosis and treatment options for megabacteria (Macrorhabdus ornithogaster). Journal of Avian Medicine and Surgery 18(3), 189-195.

Boutette J.B., Taylor M. (2004). Proventricular dilation disease: a review of research, literature, species differences, diagnostics, prognosis, and treatment. In: Proceedings of the Annual Conference of the Association of Avian Veterinarians, 175-181.
Dennison S.E., Paul-Murphy J.R., Adams W.M. (2008). Radiographic determination of proventricular diameter in psittacine birds. Journal of the American Veterinary Medical Association 232(5), 709-714.

Garcia Martinez C., Bailey T.A., Di Somma A. (2007). Radiography and image intensified fluoroscopy of barium passage through the intestinal tract of falcons. In: Proceedings of the Annual Conference of the Association of Avian Veterinarians, 508-511.

Geerinckx L., Van der Vekens E., Saunders J.H., Lautenschläger I., Van Caelenberg A.I.L. (2019). Literature review of radiographic measurements of internal organs in Psittaciformes. Journal of Exotic Pet Medicine 28(1), 60-68.

Kubiak M., Forbes N.A. (2012). Fluoroscopic evaluation of gastrointestinal transit time in African grey parrots. The Veterinary Record 171(22), 563.

Langlois I. (2003). The anatomy, physiology and diseases of the avian proventriculus and ventriculus. The Veterinary Clinics of North America. Exotic Animal Practice 6(1), 85-111.

Lightfoot T.L., Yeager J.M. (2008). Pet bird toxicity and related environmental concerns. The Veterinary Clinics of North America. Exotic Animal Practice 11(2), 229-259.

Pelelo C.J., Denson M. (1993). Proventricular dilatation syndrome in psittacines. Iowa State University Veterinarian: Digital Repository 55(2), 82-85.

Ravich M.L., Reacill D.R., Hess L., Wellehan J.F.X. (2014). Gastrointestinal cryptosporidiosis in captive psittacine birds in the United States: a case review. Journal of Avian Medicine and Surgery 28(4), 297-303.

Ritchie B.W., Gregory C.R., Latimer K.S., Pesti D. (2004). Epizootiology of proventricular dilatation disease in breeding cockatiels. In: Proceedings of the Annual Conference of the Association of Avian Veterinarians, 41-45.

Samour J. (2016). Hematology reference values table for selected avian species (Appendix 1); Blood chemistry reference values for selected avian species (Appendix 2). In: Samour J. (editor). Avian Medicine. Third edition, Elsevier, Missouri, p. 595-610.

Sladakovic I., Ellis A.E., Divers S.J. (2017). Evaluation of gastroscopy and biopsy of the proventriculus and ventriculus in pigeons (Columba livia). American Journal of Veterinary Research 78(1), 42-49.

Terio K.A., McAloose D., Leger J.S. (2018). Palaeognathae: Apterygiformes, Casuariiformes, Rheiformes, Struthioniformes, Tinamiformes. In: Terio K.A., McAloose D., Leger J.S. (editors). Pathology of Wildlife and Zoo Animals. First edition, Academic Press, London, p. 648.

Vink-Nooteboom M., Lumeij J.T., Wolvekamp W.T.C. (2003). Radiography and image-intensified fluoroscopy of barium passage through the gastrointestinal tract in six healthy Amazon parrots. Veterinary Radiology \& Ultrasound 44(1), 43-48.

Werther K., Schocken-Iturrino R.P., Verona C.E.S., Barros L.S.S. (2002). Megabacteriosis occurrence in budgerigars, canaries and lovebirds in Ribeirao Preto region - Sao Paulo state - Brazil. Brazilian Journal of Poultry Science 2, 183-187. 